\title{
Keanekaragaman Serangga Penyerbuk di Perkebunan Sayuran Kelurahan Rurukan Kota Tomohon \\ (Diversity of Pollinator Insects in the Vegetable Plantation of Rurukan, Tomohon City)
}

\author{
Samuel Masawet, Roni Koneri*), Farha N.J.Dapas \\ Jurusan Biologi, Fakultas Matematika dan IImu Pengetahuan Alam, Universitas Sam \\ Ratulangi, Manado, Indonesia \\ *E-mail: ronicaniago@unsrat.ac.id
}

Diterima 5 Juli 2019, diterima untuk dipublikasi 10 Agustus 2019

\begin{abstract}
ABSTRAK
Kehadiran serangga penyerbuk sangat berperan penting dalam proses penyerbukan. Hal ini disebabkan karena serangga tersebut mentransfer tepungsari dari anther ke stigma yang menyebabkan terjadinya pembuahan. Penelitian ini bertujuan untuk menganalisis keanekaragaman serangga penyerbuk di perkebunan sayuran di Kelurahan Rurukan Kota Tomohon. Pengambilan sampel dilakukan pada tiga tipe lahan yaitu perkebunan labu siam, wortel, dan pinggir hutan. Pada masing-masing titik pengambilan sampel dibuat tiga plot berukuran $20 \mathrm{~m} \times 20 \mathrm{~m}$ dengan jarak antar plot $20 \mathrm{~m}$. Teknik pengamatan serangga penyerbuk menggunakan metode scan sampling. Hasil penelitian didapatkan 14 famili yang terdiri dari 24 spesies dan 2.185 individu. Ordo yang paling banyak ditemukan adalah Hymenoptera, sedangkan spesies yang memiliki kelimpahan tertinggi yaitu Apis nigrocincta. Keanekaragaman spesies penyerbuk tertinggi ditemukan pada lahan perkebunan wortel. Keanekaragaman spesies penyerbuk dipengaruhi oleh tipe perbunggaan, warna bunga, bau bunga dan kandungan nektar dari bunga.
\end{abstract}

Kata kunci: Keanekaragaman, serangga penyerbuk, lahan pertanian, Desa Rurukan

\begin{abstract}
The presence of insect pollinators plays an important role in pollination processes. This is because the insects transfer the Tepungsari from anther to the stigma that causes the occurrence of fertilization. This research aims to analyse the diversity of insect pollinators in vegetable plantations in the village of Rurukan in Tomohon. Sampling was carried out on three types of land namely pumpkin plantations, carrots, and forest edges. At each sampling point was made three plots measuring $20 \mathrm{~m} \times 20 \mathrm{~m}$ with a distance between plot was $20 \mathrm{~m}$. Insect pollinators observation technique using sampling scan method. The results of the study gained 14 families consisting of 24 species and 2,185 individuals. The most widely discovered order was Hymenoptera, while the species which has the highest abundance was Apis nigrocincta. The highest diversity of the pollinator species was found on carrot plantation land. The diversity of pollinator species is influenced by the type of flowering, color of flowers, smell of flowers and the nectar content of flowers.

Keywords: Diversity, pollinators Insects, agricultural land, Rurukan village.
\end{abstract}

\section{PENDAHULUAN}

Serangga penyerbuk merupakan serangga yang berperan sebagai agen menempelnya serbuk sari pada putik
(Erniwati 2009). Penyerbukan (pollination) adalah proses transfer serbuk sari dari kepala sari (anther) ke kepala putik (stigma) (Barth 1991). 
Serangga yang berperan dalam penyerbukan sebagian besar terdiri dari ordo Hymenoptera (semut dan lebah), Coleoptera (kumbang), Lepidoptera (kupu-kupu dan ngengat), dan Diptera (lalat) (Clarisa dan Kasmara 2016). Serangga tersebut membantu penyerbukan tumbuhan berbunga, baik tumbuhan liar maupun tanaman pertanian. Peran serangga penyerbuk bagi manusia meliputi peningkatan produksi pertanian dan pelestraian tumbuhan di alam (Widhiono dan Sudiana 2015).

Tumbuhan tropis sebagian besar atau lebih dari $90 \%$ diserbukkan oleh agen penyerbuk dan dua pertiga diantaranya dilakukan oleh serangga (Siregar 2014). Serangga penyerbuk dibutuhkan karena tumbuhan tersebut tidak mampu melakukan penyerbukan sendiri (self-pollination). Penyerbukan terjadi karena serangga penyerbuk tertarik pada bunga-bunga dari tanaman tersebut. Penyerbukan pada tanaman terjadi atas bantuan serangga. Proses penyerbukan mulai dari hinggapnya serangga penyerbuk pada bunga dan menyentuh serbuk sari sehingga serbuk sari pada bunga menempel pada kaki serangga dan pada saat serangga beranjak untuk mencari sari madu pada bunga yang lain, serbuk sari yang menempel pada kaki serangga terjatuh pada kepala putik (Khartikawati 2009).

Aktivitas serangga penyerbuk mengunjungi tanaman berbunga bertujuan untuk mencari pakan, dalam hal ini bunga yang mekar mengandung zat gula (nektar) yang merupakan sumber makanan bagi serangga penyerbuk. Kehadiran serangga penyerbuk pada tanaman berbunga dipengaruhi oleh beberapa faktor antara lain warna bunga, aroma bunga, serbuk sari, nektar, bentuk bunga, ukuran bunga, jumlah bunga dan kesesuaian karakter bunga dengan tubuh serangga penyerbuk, dan dipengaruhi oleh faktor lingkungan (Asikainen dan Mutikainen 2005; Raju dan Ezradanam 2002). Namun, faktor yang sangat mempengaruhi serangga yaitu warna bunga karena serangga memiliki kemampuan mengenali warna bunga. Ketersediaan nektar dan polen yang merupakan sumber pakan serangga penyerbuk juga menjadi salah satu faktor berkunjungnya serangga penyerbuk pada bunga (Faheem et al. 2004).

Kehadiran serangga penyerbuk juga sangat dipengaruhi oleh ketersedian tumbuhan berbunga pada suatu ekosistem. Hilangnya tumbuhan berbunga dapat terjadinya penurunan serangga penyerbuk. Kerusakan hutan yang terjadi dapat menyebabkan terganggunya interaksi mutualisme antara tumbuhan dengan serangga. Dari total hewan yang telah punah, sekitar 95\% adalah avertebrata dan sebagian besarnya serangga (Myers et al. 2000). Faktor lain yang dapat menyebabkan berkurangnya serangga penyerbuk yaitu penggunaan pestida yang berlebihan dalam mengendalikan hama pada lahan pertanian (Purwatiningsih et al. 2012).

Kelurahan Rurukan yang termasuk wilayah Kota Tomohon, Sulawesi Utara merupakan salah satu wilayah yang memiliki lahan pertanian yang sebagaian besar ditanami dengan tanaman sayuran. Kehadiran serangga penyerbuk pada lahan pertanian di desa Rurukan sangat penting dalam membantu proses penyerbukan, sehingga terjadi peningkatan produksi tanaman sayuran.

Penggunaan pestisida oleh petani dalam pemberantasan hama pada tanaman sayuran akan dapat menurunkan populasi serangga penyerbuk. Hasil survei penggunaan pestisida pada tanaman pangan yang dilaksanakan pada tahun 1990 menunjukkan bahwa sebagian besar petani di Sulawesi Utara menggunakan insektisida dengan jumlah perlakuan yang melebihi persyaratan (Sembel 2010). Hal ini akan dapat menurunkan keanekaragaman seranggga 
penyerbuk pada lahan pertanian tersebut. Keanekaragaman serangga penyerbuk pada lahan pertanian di Kelurahan Rurukan, Kota Tomohon belum banyak diteliti dan dipublikasikan. Padahal data ini sangat penting dalam konservasi serangga penyerbuk pada lahan pertanian sayuran. Penelitian ini bertujuan untuk menganalisis keanekaragaman serangga penyerbuk di perkebunan sayuran di Kelurahan Rurukan Kota Tomohon.

\section{METODE \\ Waktu dan Tempat Penelitian}

Penelitian dilaksanakan pada bulan Maret 2019 sampai Mei 2019. Lokasi penelitian yaitu perkebunan Sayuran di Kelurahan Rurukan Kecamatan Tomohon Timur, Kota Tomohon Sulawesi Utara.

\section{Teknik Pengambilan Sampel}

Pengambilan sampel dilakukan pada tiga titik pengambilan sampel berdasarkan tipe penggunan lahan yaitu perkebunan labu siam, wortel, dan pinggir hutan. Pada masingmasing titik pengambilan sampel dibuat tiga plot berukuran $20 \mathrm{~m} \times 20 \mathrm{~m}$ dengan jarak antar plot $20 \mathrm{~m}$. Teknik pengamatan serangga penyerbuk menggunakan metode scan sampling (Martin, Bateson dan Bateson 1993), yaitu menghitung jumlah spesies dan individu serangga pengunjung. Serangga yang hinggap ditangkap dengan menggunakan insect net untuk keperluan identifikasi.

Pengamatan serangga penyerbuk pada setiap plot dilakukan selama 30 menit. Pengambilan sampel dilaksanakan dari jam 08.00 sampai 12.00 WITA karena kelembaban udara yang optimal pada saat cuaca dingin di pagi hari, dan puncak aktivitas kunjungan serangga penyerbuk tertinggi pada siang hari dari jam 10.00-12.00 WITA ketika cuaca cerah (Wolda dan Sabrosky 1986). Identifikasi serangga penyerbuk yang diperoleh di lokasi pengambilan sampel di lakukan di Laboratorium Ekologi dan Biokonservasi, Jurusan Biologi, FMIPA Unsrat. Buku identifikasi yang digunakan yaitu buku kunci determinasi serangga oleh Kanisius (1991). Borror et al. (1992), Lewis (1973), dan Michener (2000).

Pengukuran

parameter lingkungan dilakukan pada setiap waktu pengamatan serangga di lokasi penelitian. Faktor lingkungan yang mempengaruhi kunjungan serangga penyerbuk diantaranya adalah suhu udara dan kelembaban udara. Suhu dan kelembaban udara diukur dengan menggunakan termohygrometer.

\section{Analisis Data}

Data yang dilakukan meliputi kelimpahan spesies (N), Indeks kekayaan spesies (S), indeks keanekaragaman spesies $\left(H^{\prime}\right)$, indeks kemerataan spesies (E) dan indeks kesamaan jenis (S). Indeks kekayaan spesies menggunakan menggunakan rumus indeks Richness (Soetjipto 1993):

$\mathrm{R}=\frac{S-I}{\mathrm{In} . N} ; \mathrm{R} \quad$ : Indeks Richness, $S$ : Jumlah spesies ( $\mathrm{n} 1, \mathrm{n} 2$, $n 3, \ldots ..), \quad N$ : Total individu dalam pengambilan sampel

Magurran (1998) menyatakan bahwa kriteria yang digunakan untuk menginterpretasikan kekayaan Richness yaitu: $<3,5=$ kekayaan spesies; rendah; 3,5 - 5 = kekayaan spesies sedang; > $5=$ kekayaan spesies tinggi.

Indeks keanekaragaman spesies Shannon-Wiener (Stiling, 2002) sebagai berikut: $\mathrm{H}^{\prime}=-\sum p i \operatorname{In} p i$; $\mathrm{p}_{\mathrm{i}}=$ $\mathrm{n}_{\mathrm{i}} / \mathrm{N}$ (rasio jumlah individu suatu jenis terhadap keseluruhan jenis), $\mathrm{n}_{\mathrm{i}}=$ Jumlah individu spesies ke-i, $\mathrm{N}=$ Total individu. Indeks keanekaragaman spesies menurut Shannon-Wiener dalam (Fachrul. 2006) didefinisikan sebagai berikut: Nilai $\mathrm{H}^{\prime}>3$ menunjukan bahwa keanekaragaman spesies tinggi, Nilai $H^{\prime} 1 \leq H^{\prime} \leq 3$ 
menunjukan bahwa keanekaragaman spesies sedang, Nilai $H^{\prime}<1$ menunjukan bahwa keanekaragaman spesies rendah.

Indeks kemerataan spesies digunakan indeks kemerataan Eveness (Odum,1996), sebagai berikut :Indeks kemerataan spesies : $\mathrm{E}$ $=\frac{H^{\prime}}{\operatorname{Ln} \mathrm{S}}, \quad H^{\prime}=$ Indeks Shannon-Wiener, $S=$ Jumlah spesies. H' maksimum akan terjadi apabila ditemukan di mana semua jenis melimpah. Nilai $E$ memiliki kisaran antara 0 dan 1 yang mana nilai 1 menunjukan suatu keadaan di mana semua jenis cukup melimpah (Fachrul, 2006).

\section{HASIL DAN PEMBAHASAN \\ Komposisi Spesies Serangga Penyerbuk}

Serangga penyerbuk yang ditemukan dalam penelitian ini sebanyak 4 ordo, 14 famili, 22 genus, 24 spesies, dan 2.185 individu (Tabel 1). Empat Ordo yang ditemukan yaitu Coleoptera, Diptera, Hymenoptera, dan Lepidoptera. Ordo yang paling banyak ditemukan adalah Hymenoptera dengan prosentase 58\% dan yang terendah Lepidoptera sebanyak 6\% (Gambar 1).

Ordo Hymenoptera banyak ditemukan karena ordo ini sebagian besar berfungsi sebagai penyerbuk. Menurut Atmowidi (2007) banyaknya Ordo Hymenoptera ditemukan pada perkebunan labu siam karena serangga penyerbuk yang paling penting perannya dalam melakukan penyerbukan tanaman yaitu lebah yang termasuk dalam famili Apidae. Famili serangga penyerbuk yang paling banyak ditemukan yaitu Apidae sebesar 47\% dan Sryphidae 18\%, sedangkan famili yang paling sedikit adalah Vespidae, Papilionidae, Pieridae, Erebidae, dan Cantharidae (Gambar 2).

Berdasarkan tipe lahan didapatkan bahwa kelimpahan famili
Apidae mendominasi pada semua habitat. Famili Apidae pada tanaman labu siam ditemukan sebanyak 263 individu, tanaman wortel sebanyak 382 individu, dan pinggir hutan sebanyak 362 individu. Famili berikutnya yang memiliki kelimpahan tertinggi yaitu Syrphidae pada tanaman labu siam ditemukan 104 individu, tanaman wortel ditemukan 215 individu, dan pinggir hutan ditemukan 71 individu (Tabel 1) Famili Apidae dan Syrphidae merupakan jenis serangga yang ditemukan pada saat pengamatan tergolong tinggi karena keadaan bunga yang sedang mekar dan juga ketersediaan makanan yang tinggi (Ollerton dan Liede 1997).

Jumlah Genus serangga penyerbuk yang ditemukan pada lokasi penelitian berjumlah 22 genus. Syrphidae dan Nymphalidae masingmasing terdiri dari empat genus, Calliphoridae dan Scarabaeidae masing-masing terdiri dari dua genus, sedangkan Cantharidae, Carabidae, Crambidae Erebidae, Formicidae, Papilionidae, Pieridae, Tiphiidae, Apidae, dan Vespidae masing-masing terdiri dari satu genus (Tabel 1). Genus Apis merupakan genus dengan jumlah spesies terbanyak yaitu tiga spesies.

Spesies serangga penyerbuk yang memiliki jumlah individu terbanyak yaitu Apis nigrocincta sebanyak $19,31 \%$ dan diikuti oleh Apis mellifera $(14,28 \%)$. Spesies dengan jumlah individu paling sedikit adalah Rhagonycha fulva sebanyak dua individu atau (0,09\%) kemudian Syrphus rectus juga memiliki dua individu atau $(0,09 \%)$. Berdasarkan titik lokasi penelitian ditemukan bahwa kelimpahan individu serangga penyerbuk yang tertinggi terdapat pada tanaman wortel (1.185 individu) kemudian pada tanaman labu siam sebanyak (535 individu) (Tabel 1). 
Tabel 1. Jumlah Ordo, Famili dan spesies serangga penyerbuk pada tiga lokasi pengamatan di kawasan perkebunan sayuran Desa Rurukan.

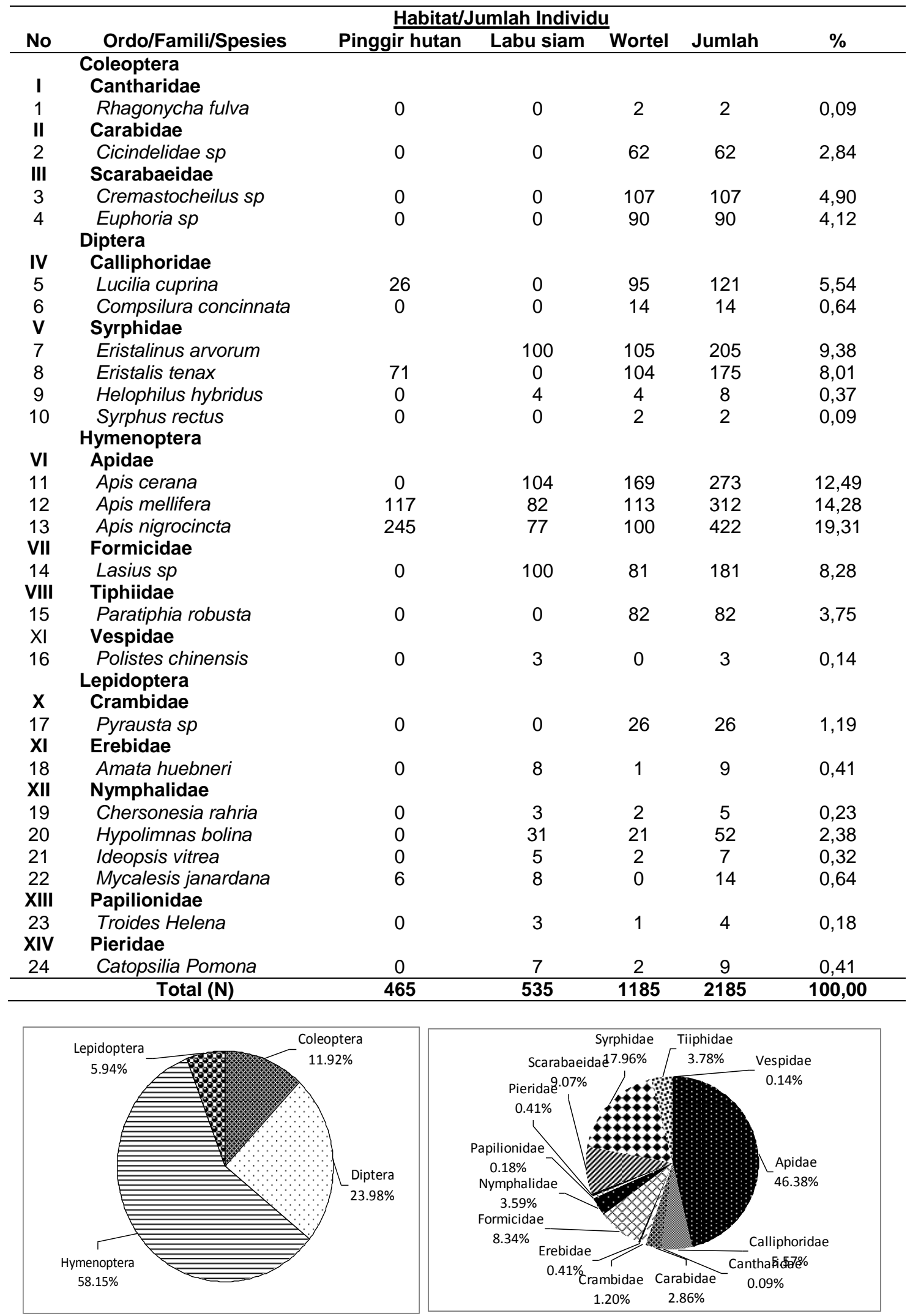

Gambar 1. Kelimpahan Ordo serangga

Gambar 2. Kelimpahan Famili serangga penyerbuk penyerbuk 
Jumlah spesies pada lokasi pinggir hutan yaitu lima spesies terdiri dari Lucilia cuprina, Eristalis tenax, Apis mellifera, Apis nigrocincta, dan Mycalesis janardana. Spesies serangga penyerebuk yang ditemukan pada lokasi tanaman labu siam terdapat 14 spesies yaitu Eristalinus arvorum, Helophilus hybridus, Apis cerana, Apis mellifera, Apis nigrocincta, Lasius sp, Polistes chinensis, Amata huebneri, Chersonesia rahria, Hypolimnas bolina, Ideopsis vitrea, Mycalesis janardana, Troides helena, dan Catopsilia pomona.

Spesies serangga penyerbuk yang ditemukan pada tanaman wortel terdapat 22 spesies yaitu Rhagonycha fulva, Cicindelidae sp, Cremastocheilus sp, Euphoria sp, Lucilia cuprina, Compsilura concinnata, Eristalinus arvorum, Eristalis tenax,Helophilus hybridus, Syrphus rectus, Apis cerana, Apis mellifera, Apis nigrocincta, Lasius sp, Paratiphia robusta, Pyrausta sp, Amata heubneri, Chersonesia rahria, Hypolimnas bolina, Ideopsis vitrea, Troides helena, dan Catopsilia pomona (Table 1). Penemuan spesies tertinggi pada tanaman labu siam yaitu Apis cerana sebanyak 104 individu.
Pada tanaman wortel spesies yang tertinggi juga ditemukan spesies Apis cerana sebanyak 169 individu. Sedangkan pada pinggir hutan jumlah penemuan spesies yang tertinggi adalah Apis nigrocincta sebanyak 245 individu (Tabel 1). Kelimpahan serangga dalam suatu habitat ditentukan oleh kelimpahan pakan maupun sumberdaya lain yang tersedia pada habitat tersebut (Saragih 2008).

Kehadiran serangga penyerbuk pada tanaman berbunga dipengaruhi oleh beberapa faktor antara lain warna bunga, aroma bunga, serbuk sari, nektar, bentuk bunga, ukuran bunga, jumlah bunga dan kesesuaian karakter bunga dengan tubuh serangga penyerbuk, dan faktor lingkungan (Asikainen dan Mutikainen 2005; Raju dan Ezradanam 2002).

\section{Keanekaragaman Serangga Penyerbuk}

Indeks kekayaan spesies (R) serangga penyerbuk yang tertinggi ditemukan pada tanaman wortel dengan nilai yaitu 2,97 kemudian diikuti oleh tanaman labu siam 2,03. Indeks kekayaan spesies terendah terdapat di lokasi pinggir hutan dengan nilai 0,65 (Gambar 3).

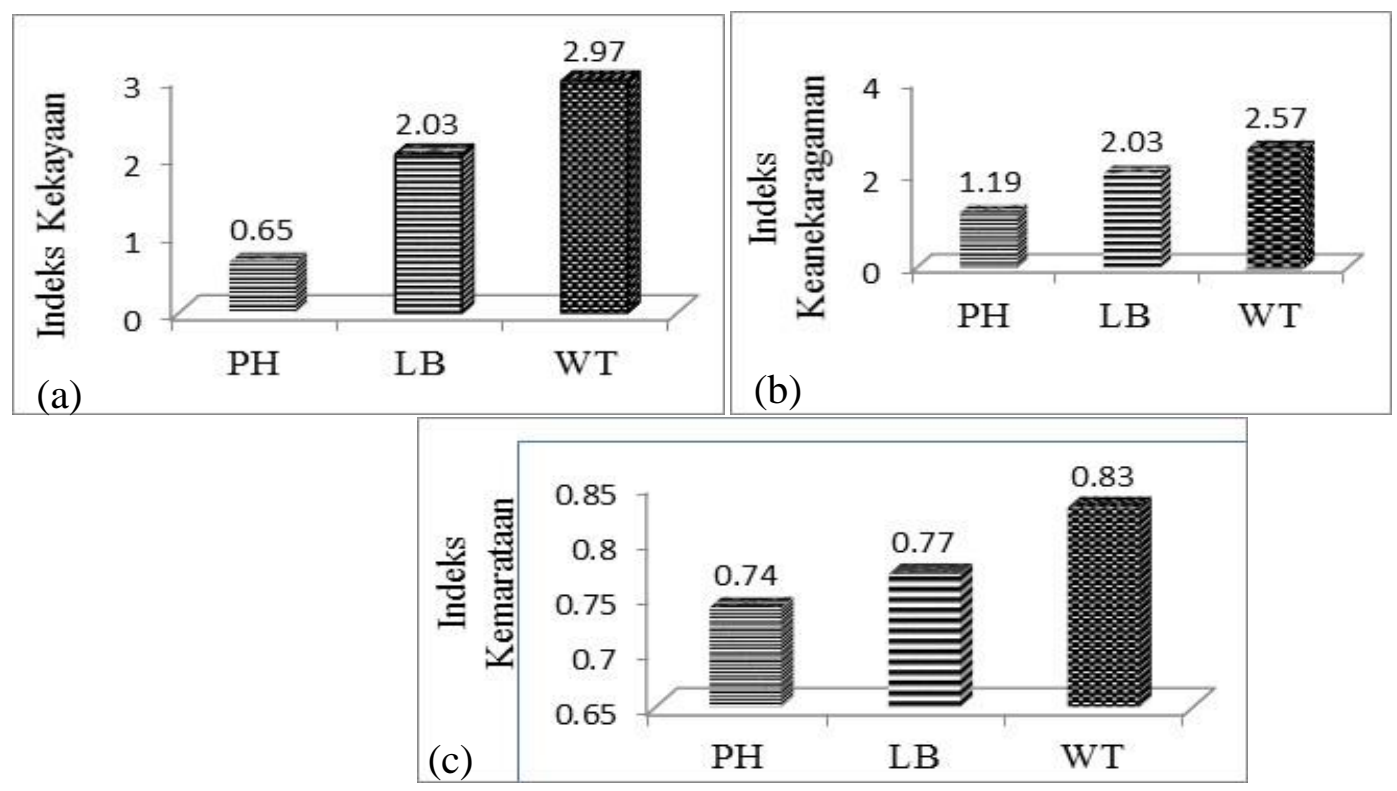

Gambar 3. Indeks kekayaan spesies (a), indeks keanekaragaman spesies (b), indeks kemerataan spesies (c) pada tiga lokasi pengamatan (PH: Pinggir Hutan, LB: Lahan Perkebunan, WT: Lahan Wortel ) 
Indeks kekayaan spesies yang ditemukan pada perkebunan sayuran Desa Rurukan Kecamatan Tomohon Timur Kota Tomohon tergolong rendah karena nilai indeks kekayaan spesiesnya kecil dari 3,5. Menurut Maguran (1988), jika nilai $<3,5$ tergolong rendah, nilai $>3,5-5$ tergolong sedang dan nilai $>5$ tergolong tinggi.

Indeks keanekaragaman spesies $\left(H^{\prime}\right)$ serangga penyerbuk tertinggi ditemukan pada perkebunan wortel sebesar 2,57 selanjutanya pada perkebunan labu siam $(2,03)$ dan indeks keanekaragaman spesies terendah terdapat pada lokasi pinggir hutan (1,19) (Gambar 3). Keanekaragaman serangga penyerbuk di Desa Rurukan Kecamatan Tomohon Timur tergolong sedang. Menurut Fachrul (2006), jika nilai $H^{\prime}<1$ menunjukan bahwa keanekaragaman spesies rendah, jika nilai $H^{\prime} 1 \leq H^{\prime} \leq 3$ menunjukan bahwa keanekaragaman spesies sedang, jika nilai $H^{\prime}>3$ menunjukan bahwa keanekaragaman spesies tinggi. Indeks kemerataan spesies $(\mathrm{E})$ serangga penyerbuk tertinggi ditemukan pada perkebunan wortel yaitu sebesar 0,83 dan diikuti pada perkebunan labu siam dengan nilai 0,77 (Gambar 3). Indeks kemerataan spesies terendah terdapat pada lokasi pinggir hutan dengan nilai yaitu 0,74 . Indeks kemerataan spesies serangga penyerbuk pada lokasi tanaman wortel dikategorikan tinggi, sedangkan pada tanaman labu siam dan pinggir hutan tergolong sedang.

Hasil ini menunjukan bahwa beragam komoditas pada lahan pertanian dapat menjamin berlangsungnya proses penyerbukan yang dilakukan serangga. Perbedaan spesies tanaman pada suatu komunitas, tanaman dapat bergantian dalam masa pembungaan bisa juga disebut bahwa tanaman berlomba untuk mendapat kunjungan serangga (Brown et al., 2002).

\section{KESIMPULAN}

Jumlah spesies seranga penyerbuk yang ditemukan pada kawasan lahan pertanian Desa Rurukan Kecamatan Tomohon Timur Kota Tomohon didapatkan 14 famili 24 spesies dan 2.185 individu. Spesies serangga penyerbuk yang dominan ditemukan adalah Apis nigrocincta dan diikuti oleh Apis mellifera. Spesies dengan jumlah individu paling sedikit adalah Rhagonycha fulva kemudian Syrphus rectus. Ordo yang memiliki kelimpahan tertinggi adalah Hymenoptera, sedangan Apidae merupakan famili yang paling banyak ditemukan. Kelimpahan spesies, indek kekayaan spesies, indek keanekaragaman spesies dan indek kemerataan spesies serangga penyerbuk tertinggi ditemukan pada lahan tanaman wortel, sedangkan yang terendah di pinggir hutan.

\section{DAFTAR PUSTAKA}

Asikainen E, Mutikainen P (2005) Preferences of pollinators and herbivores in gynodioecious Geranium sylvaticum. Annals of Botany 95(5): 879-886.

Atmowidi T (2007) Diversity of Pollinator Insect in Relation of seed set of Mustard (Brassica rappa L.: Crusiferae.) Hayati J. Biosci 14: 155-161.

Barth FG. (1991) Insects and Flowers: The Biology dan Partnership. Princeton Univ $\mathrm{Pr}, \quad \mathrm{New}$ Jersey.Bailey, J. A. 1984. Parciples of Wildlife Management. Jhon Wiley and Sons, New York.

Brown BJ, Mitchel RJ, Graham SS 2002. Compettion for Pollination Between an Invasive Species and Native Congener. Ecology 83: 2328-2336.

Borror DJ. Johnson NF, Triplehorn CA (1992) Pengenalan Pelajaran Serangga. Diterjemahkan oleh Suryobroto, M. Gadjah Mada University Press, Jogjakarta. 
Clarisa D. Kasmara, H. (2016). Keanekaragaman serangga penyerbuk tanaman mentimun (Cucumis sativus L.) di Balai Penelitian Tanaman Sayuran (Balitsa), Lembang, Jawa Barat. In Prosiding Seminar Nasional MIPA Jatinangor (pp. 27-28).

Erniwati E (2009) Keanekaragaman dan Sebaran Serangga di Kawasan Pulau-pulau Kecil Taman Nasional Karimunjawa [Diversity dan Distribution of Insects in Small Islands of Karimunjawa National Park]. Berita Biologi 9(4).

Fachrul MF. (2006) Metode Sampling Bioekologi. Bumi Aksara, Jakarta.

Faheem M, Aslam M, Razaq M (2004) Pollination ecology with special reference to insects a review. Journal of Research Science 15(4): 395-409.

Khartikawati NK (2009) Polinator Pada Tanaman Kayu Putih. Balai Besar Penelitian Bioteknologi dan Pemuliaan Tanaman Hutan Yogyakarta.

Lewis T (1973) Thrips, Their Biology, Ecology dan Economic Importance. London: Academic Press Inc. Itd.

Magurran AE (1998) Ecological Diversity and Its Measurements. Croom Helm Limited. London.

Martin P, Bateson PPG, Bateson P (1993) Measuring behaviour: an introductory guide. Cambridge University Press.

Michener CD (2000) The Bees of The World. Baltimore: The Johns Hopkins University Press.

Myers N, Mittermeier RA, da Fonseca GAB, Kent J (2000) Biodiversity hotspots for conservation priorities. Nature 403:853-858

Odum EP (1996) Dasar-Dasar Ekologi. Edisi ke-3. Gadjah Mada University Press, Indonesia.

Ollerton J, Liede S (1997). Pollination system in the Asclepiadaceae a survey and preliminary analysis. Bio Linn Soc 62: 593-610.
Purwantiningsih $\mathrm{B}$, Amin, $\mathrm{SH}$, Bagyo $\mathrm{Y}$ (2012) Kajian Komposisi Serangga Polinator Pada Tumbuhan Penutup Tanah Di Poncokusumo. Program Pascasarjana Universitas Brawijaya, Malang

Raju AJS, Ezradanam V (2002) Pollination ecology and fruiting behaviour in a monoecious species, Jatropha curcas L. (Euphorbiaceae). Current Science 83:1395-1398.

Saragih A (2008) Indeks Keanekaragaman Jenis Serangga Pada Tanaman Stroberi (Fragaria sp.) di Lapangan. Skripsi. Medan: Jurusan Ilmu Hama dan Penyakit Tumbuhan. Fakultas Pertanian. Universitas Sumatera Utara.

Sembel DT (2010) Pengendalian Hayati. Andi Offset Yogyakarta.

Siregar EH (2014) Keanekaragaman Dan Kelimpahan Serangga Polinator Pada Tipe Penggunaan Lahan Berbeda Di Jambi, Sumatera. Sekolah Pascasarjana IPB, Bogor.

Soetjipta (1993) Dasar-Dasar Ekologi Hewan. Jakarta: Departemen Pendidikan Dan Kebudayaan Direktorat Jenderal Pendidikan Tinggi. Proyek Pembinaan Tenaga Kependidikan Pendidik Tinggi.

Stiling P (1992) Ecology Theories dan Application. Second Edition. Prientice Hall Internasional, New Jersey.

Widhiono IE, Sudiana (2015) Peran Tumbuhan Liar Dalam Konservasi Keragaman Serangga Penyerbuk Ordo Hymenopter The Role Of Wild Plants In The Conservation Of Pollinating Insects Of The Order Hymenoptera. Pross Sem Nas Masy biodiv Ind. 1(7): 2407-8050

Wolda H, and Sabrosky CW (1986) Insect Visitor to Two Form of Aristolochia pilosa in Los Cumbres Panama. Biotropica 18 (4): 295299. 